$\xi_{p}=$

\title{
Conception of Logistics Management System for Smart Factory
}

\author{
Zhen Quan Chong ${ }^{1 *}$, Cheng Yee Low ${ }^{2}$, Ubaidullah Mohammad ${ }^{3}$, Ramhuzaini Abd Rahman', \\ Mohd Saiful Bahari Shaari ${ }^{5}$ \\ ${ }^{1}$ Department of Mechanical and Manufacturing Engineering, Universiti Tun Hussein Onn Malaysia, 86400 Parit Raja, Malaysia. \\ ${ }_{2}^{2}$ Advanced Technology Training Center (ADTEC) Shah Alam, 40460 Shah Alam, Selangor, Malaysia \\ ${ }^{I}$ Faculty of Mechanical Engineering, Universiti Teknologi MARA, 40450 Shah Alam, Selangor, Malaysia. \\ *Corresponding author E-mail: saifulbahari@salam.uitm.edu.my
}

\begin{abstract}
An interconnected, data driven smart logistics management system is crucial in a smart factory in context of Industry 4.0. Applying the concept of cyber-physical systems (CPSs) and Internet of Things (IoT) will create a standardized logistics system. This system can be applied across the supply chain to enable the sharing of information in real-time which consequently optimize logistics processes. In this project, a conceptual model of a smart logistics management system between a supplier and a manufacturer using NFC smart tags technology is developed and its application is shown using prototype demonstrator. The system is equipped with functions to monitor and manage logistic related data. The interface is built using windows form application and android phone application. The developed model's abilities and specifications in context of industry 4.0 is evaluated using the VDMA Toolbox Industry 4.0. In the end this system achieved an average of level 4 in the Industry 4.0 evaluation and this system provides a concept on applying a smart logistic management system for manufacturers as a key step in transforming into smart factories.
\end{abstract}

Keywords: Smart factory; smart logistics management system; Industry 4.0; NFC; windows form application; android application.

\section{Introduction}

In the brick of the next industrial revolution, manufacturing systems are now upgraded into a more dynamic, interconnected, data driven or in another word smarter. A smart manufacturing system employs sophisticated manufacturing technologies and implies the exchange of data within the supply chain. This could lead to a flexible,

intelligent and customizable manufacturing system to compete in the digital age of today's global market. Operation of a smart factory involves Cyber-Physical Systems (CPSs), cloud computing and Internet of Things (IoT). These technologies enable information exchange across the supply chains including between small industries and large enterprise, making smart decisions by real-time communication between machines, sensors and humans[1].

A smart factory can provide a flexible and adaptive production system to solve problems arising from the increasing complexity and rapidly changes of product today. It deploys automation technologies with a combination of hardware, software and mechanics leading to a more optimized manufacturing process. Unnecessary waste of resources can be reduced by employing automation and creating a dynamic network linking together different industrial and non-industrial partners[2][3].

Logistics management is the core of modern supply chain management, as it serves as a platform between the point of origin and the point of consumption. Its operational efficiency will directly

impact the overall efficiency of the supply chain. In term of Industry 4.0, logistics management system needs to add the right level of autonomy and intelligence by striking the right balance between man and machine and the end goals in function of changing ecosystem demands[4].

Therefore, employing smart system to manage data exchange will speed up logistics. A smart logistic management system is an inextricably linkage of logistics operations and information systems with the continuous emergence of new technology and new flow[5]. Manufacturers must rely on smart logistics management system in order to improve the efficiency of the logistics operation thus

speeding up the manufacturing processes, save production cost and ensure product quality[6].

In this paper, a concept of a smart logistic management system is discussed briefly. The idea is to bridge the gap between manufacturers and suppliers where a prototype system is developed to demonstrate the concept and how it works. The prototype uses near field communication (NFC) tags as identification of objects and update it onto a database hosted in a cloud.

The rest of the paper is organized as follows. Section 2 outlines the smart logistics management system concept. Section 3 will discuss the requirement and specification of the system. Section 4 will explain about the development of a database for the system. Section 5 will discuss the system prototype and section 6 will explain about the evaluation. Lastly a conclusion will be drawn.

\section{Conceptualize of Smart Logistics Manage- ment System}

The basic components that foster a smart logistic system are the identification, locating, sensing of the goods. In this project, the main focus is to conceptualize a smart logistics management system in a smart factory by implementing technologies that enables 
real-time communication for material supply between suppliers and manufacturers.

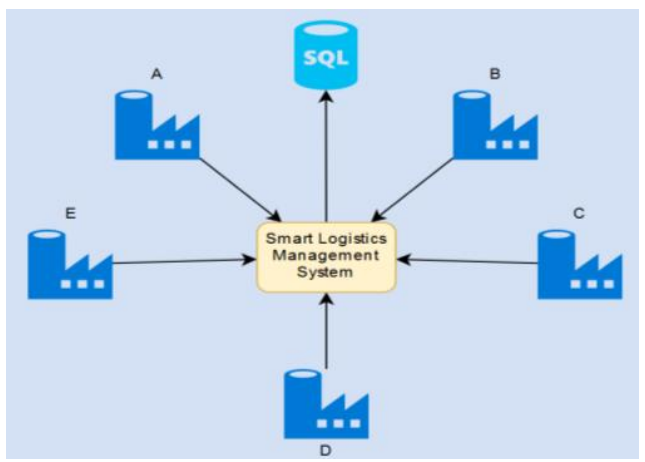

Fig. 1: Overview smart logistics management system

Fig. 1 shows a scenario where there are several manufacturers in them will supply to a manufacturer or to each other materials depending on their needs.

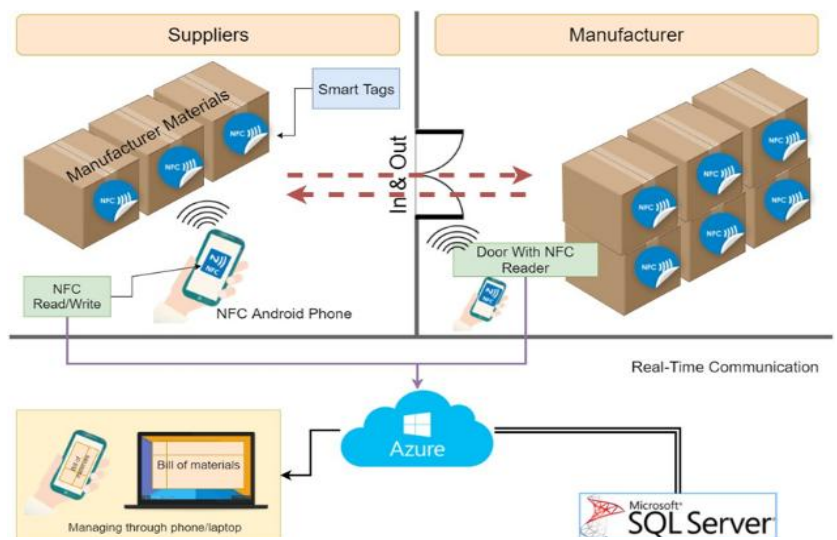

Fig. 2: Conceptual illustration of smart logistics management system

Fig. 2 shows the basic concept of this smart logistics management system. The integration of smart tags and cloud services into the logistics management system is the key point in this concept. Smart tags enable the system to track the incoming and outgoing of manufacturing materials while cloud services act as a medium that manage all the related information. the smart logistics management system platform where some of

Fig. 3 shows the flow chart of the overall concept of this smart logistics management system. The system consists of two different function applications namely:

1. Monitoring Application

- Monitor the stock in warehouse

- Add materials from other manufacturers' products

- Add product ready to order by other manufacturers

- Auto order system

2. Managing Application

○ Read the smart tags' serial number

- Write the smart tags' serial number

- Accept stock (In/Out)

$\circ \quad$ Monitoring materials in warehouse

Initially, supplier will receive order from a manufacturer through the monitoring application. Manufacturing materials will be prepared by the supplier and the information is updated into a database by the monitoring application. A unique serial number is generated according to the material information and written into smart tags. These smart tags are attached to the materials before shipping out to the manufacturer. Each smart tag consists of a unique serial number that can be read by smart devices that has the managing application.

Whenever the materials reach the manufacturer site, the information will automatically be updated into the system through a smart tags reader at the entrance. The managing application will retrieve information pertaining the materials such as the material's name, quantity, date of shipment, the serial number which is stored in the database.

SQL Database will be built using Relational Database Management System (RDBMS)[7]. All the relevant data is stored in tables in the RDBMS. Personal either from the supplier or the manufacturer which is granted access to the system can connect to the server to retrieve the related data.

Nevertheless, a mutual understanding and agreement between suppliers and manufacturers must firstly be established in order to successfully transform into a smart system. This will ensure the transparency of information within the whole supply chain management system. This will standardize all the require logistics information within the entire framework of suppliers and manufacturers.

\section{Requirements and Specifications}

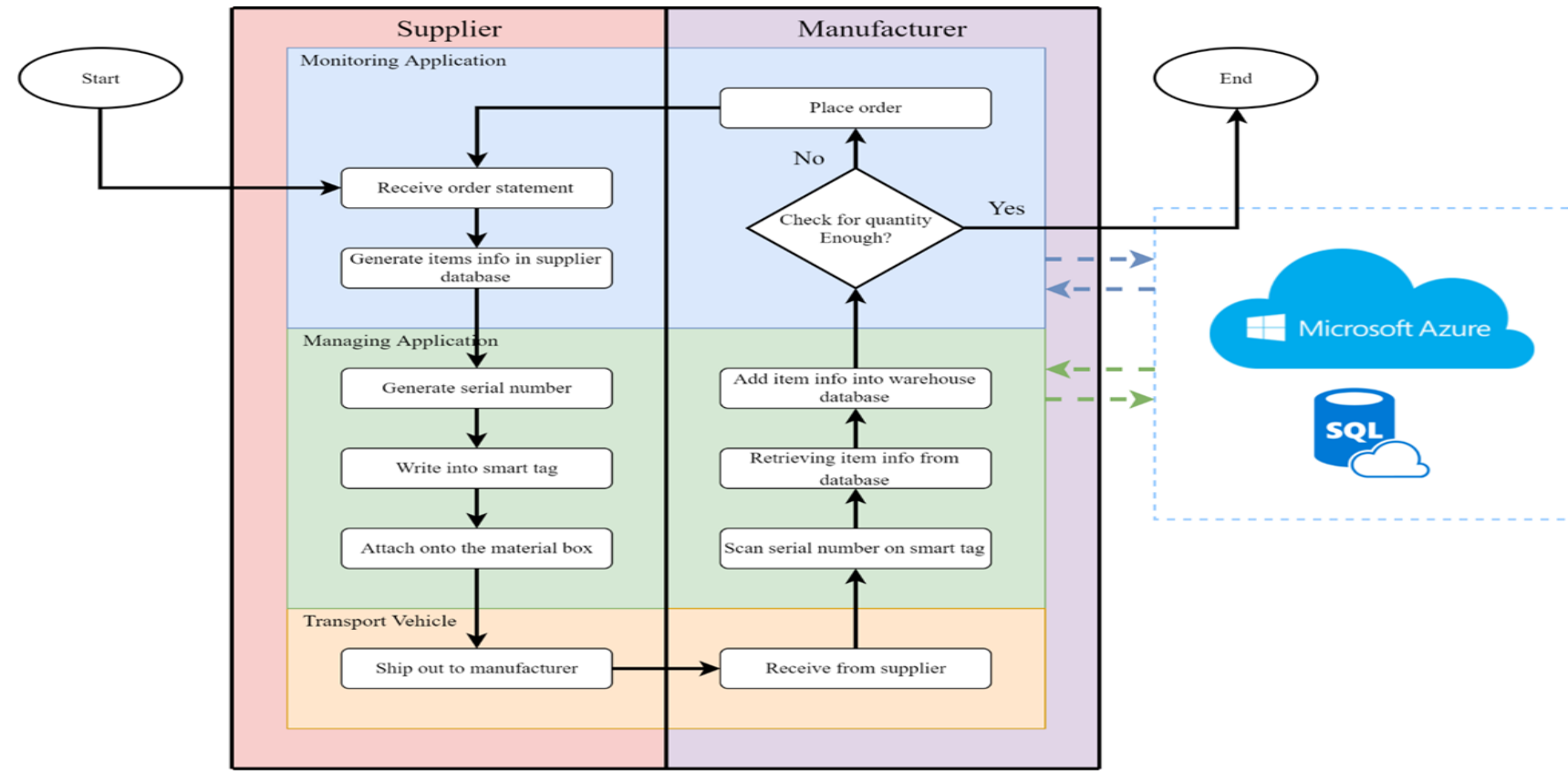

Fig. 3: Flow chart of the concept 
Based on the conceptualized smart logistics management system model, there are few requirements that need to be included in the system where they are divided into functional and non-functional requirements.

\subsection{Functional Requirements}

1. User is able to create an account.

2. User is able to view materials

3. User is able to view orders.

4. User is able to view products.

5. User is able to add materials.

6. User is able to add orders.

7. User is able to add products.

8. User is able to edit a material requires quantity.

9. User is able to turn on and off the auto order function.

10. User is able to set auto order quantity.

11. User is able to remove materials.

12. User is able to remove products.

13. User is able to cancel orders.

14. User is able to arrange orders.

15. User is able to ship orders

16. User is able to receive orders.

17. User is able to use materials.

\subsection{Non-Functional Requirements}

1. The user interface should be user friendly.

2. The windows application should be compatible with Windows 7 or above.

3. The mobile application should be compatible with Android Version 5.0 or above.

4. The system is able to validate all the inputs.

5. The system is able to make order automatically.

6. The system is able to show user real-time data.

7. The system is able to connect with online database.

\subsection{System Specification}

The smart logistics management system uses SQL database and two other applications for the monitoring application and managing

application. The detailed specifications of these components are shown in Table 1. Table 1 shows all the specifications of each component in the smart logistics management system.

Table 1: Specification of each component

\begin{tabular}{|c|c|c|}
\hline Component & \multicolumn{2}{|l|}{ Specification } \\
\hline \multirow{6}{*}{$\begin{array}{c}\text { SQL } \\
\text { database }\end{array}$} & \multicolumn{2}{|c|}{ Microsoft Azure SQL Database } \\
\hline & & $\begin{array}{l}\text { Microsoft SQL Server } \\
\text { Management Studio } 2017\end{array}$ \\
\hline & Location & Southeast Asia \\
\hline & Subscription & Microsoft Imagine \\
\hline & Server name & olaflafv1.database.windows.net \\
\hline & Size & $32 \mathrm{MB}$ \\
\hline \multirow{5}{*}{$\begin{array}{l}\text { Monitoring } \\
\text { Application }\end{array}$} & \multicolumn{2}{|c|}{ Windows Form Application } \\
\hline & IDE & Visual Studio Community 2017 \\
\hline & Language & $\mathrm{C} \#$ \\
\hline & $\begin{array}{l}\text { Target } \\
\text { Framework }\end{array}$ & 4.6 .1 \\
\hline & Output Type & Windows Application \\
\hline \multirow{5}{*}{$\begin{array}{l}\text { Managing } \\
\text { Application }\end{array}$} & \multicolumn{2}{|c|}{ Android Phone Application } \\
\hline & IDE & Visual Studio Community 2017 \\
\hline & Language & Xamarin \\
\hline & $\begin{array}{l}\text { Minimum } \\
\text { Android Ver- } \\
\text { sion }\end{array}$ & $\begin{array}{l}\text { Android } 5.0 \text { (API Level } 21 \text { - Lolli- } \\
\text { pop) }\end{array}$ \\
\hline & Output Type & Android Application \\
\hline
\end{tabular}

\subsection{System Architecture}

The smart logistics management system is structured into a threelayered architecture as shown in Fig. 4. Both applications have different UI components for the presentation layer as both have different control function. However, they shared the same business layer and data layer due to the same backend function towards the SQL database.

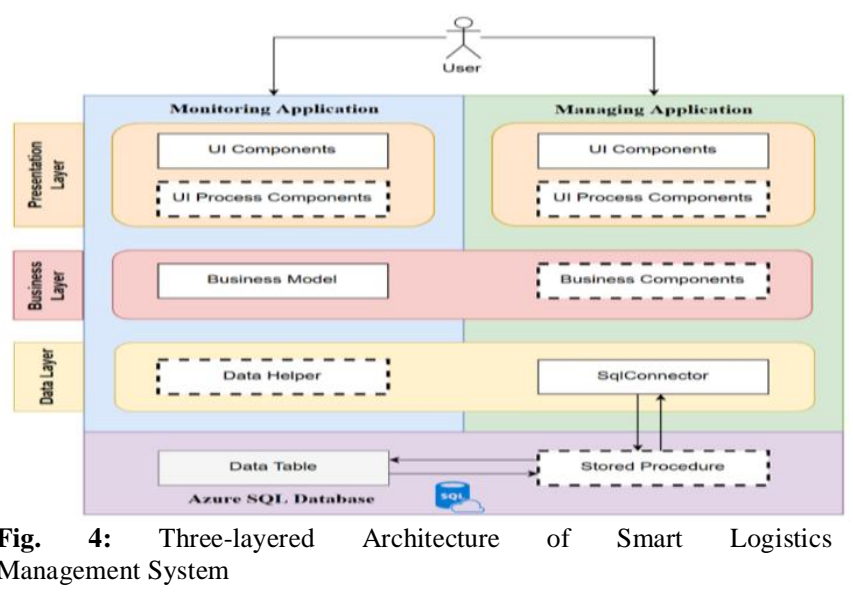

\section{Database Development}

\subsection{Entity Relational Diagram (ERD)}

Fig. 5 shows the ERD diagram of the Smart Logistics Management System. The system consists of four data tables and each of them is related to each other. All the entries require in the data tables are based on the functional requirements for the users integrate to each other in the system.

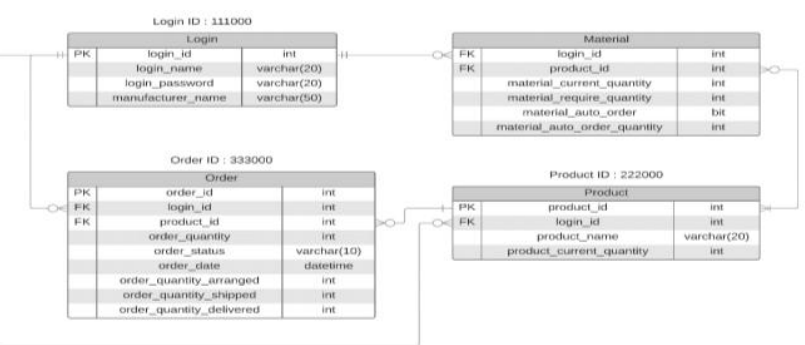

Fig. 5: ERD Diagram

\subsection{Class Diagram}

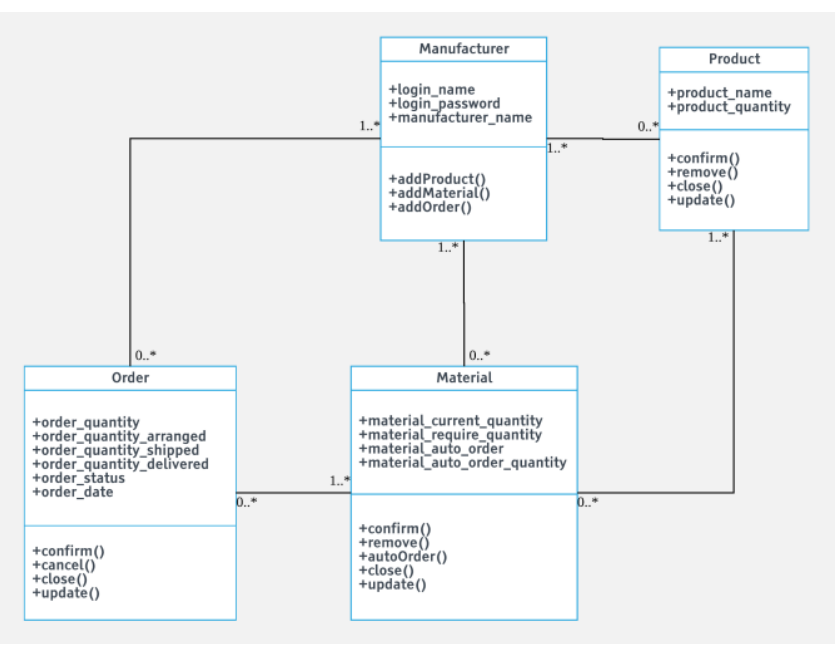

Fig. 6: Class diagram 
Fig. 6 shows the class diagram of the prototype monitoring application. There are four main classes according to the ERD diagram which are Login, Product, Material and Order classes. The Login class is used to store and retrieve user information from the database. Each user own zero to several products, materials and orders. The Product class contains all the product entries of the user and can be stored and retrieved to the product table. Material class is used to store and retrieve the information of material entries while Order class is used to store and retrieve the order entries.

\section{Demonstration Model}

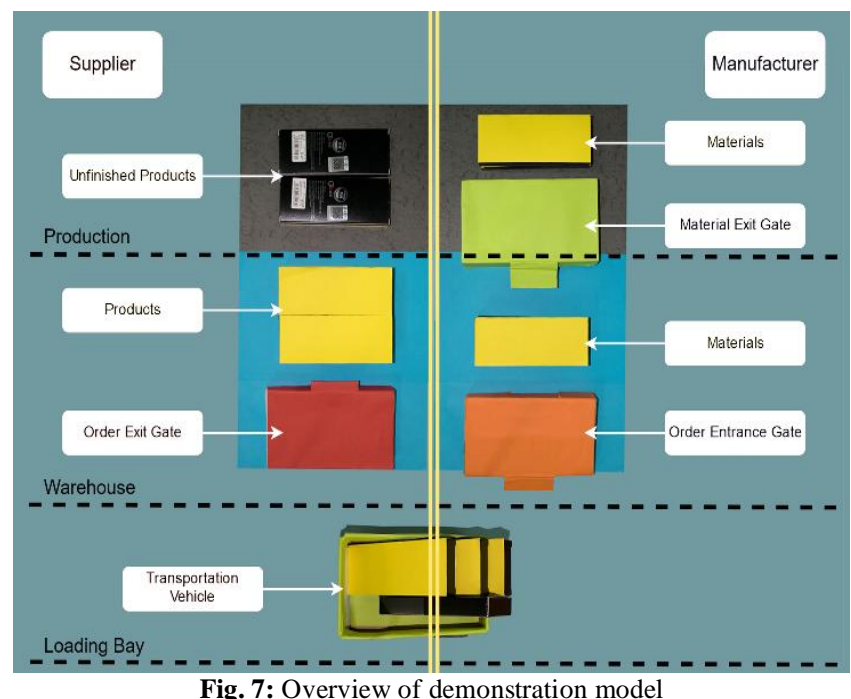

Fig. 7 shows the demonstration model that has been developed throughout this project based on the conceptualize model in Fig. 3. In this demonstration model, there are two parties involves which are the supplier and the manufacturer. There are three gates in the model which are the supplier's warehouse exit, the manufacturer's warehouse entrance and material exit. The products are attached with NFC tags. Smart phones with the managing application will act as the gate with sensors that will read all the smart tags in the products that pass through the gate. Therefore, the information and order status of the product or material that has passed through the gate will be updated to an Azure SQL Server in the cloud.

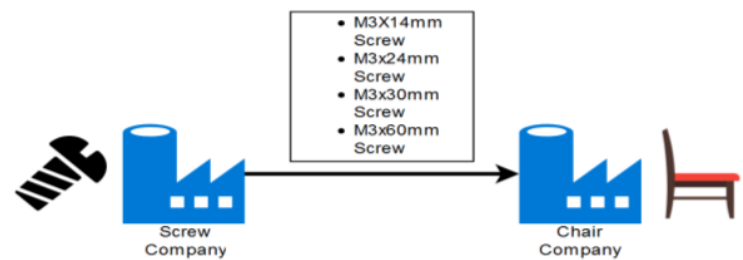

Fig. 8: Supplier and manufacturer relation

A scenario has been created to demonstrate the smart logistics management system in this demonstration model. Fig. 8 shows a scenario where Chair Company is getting supplies from Screw Company for 4 types of screws. Both companies have already established a business relation and agreement for a long period of time and have agreed to transform their factory to a smart factory to increase the productivity with the implementation of Industry 4.0 framework in the country mainly in the logistic system.

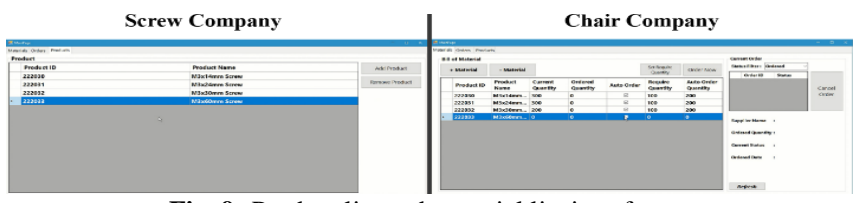

Fig. 9: Product list and material list interface
In this demonstration, the screw company as the supplier adds screws needed by the chair company to their product supply list and subsequently will appear to the material list of the chair company as shown in Fig. 9.

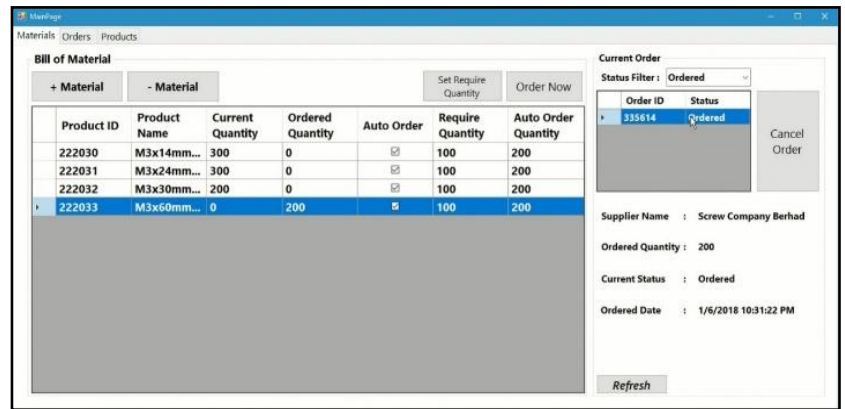

Fig. 10: Order of $M 3 \times 60 \mathrm{~mm}$ screw

From the material list, the order of the materials can be carried out either manually or automatically through the windows monitoring application. The chair company need to set the require quantity and auto order quantity when activating the auto order function. The system will immediately compare the current quantity and the require quantity of the material in the company's warehouse. Order is made based on the auto order quantity that has been set when activating the auto order function. Fig. 10 shows the order of M3x60 $\mathrm{mm}$ screw that was made using the auto order function where require quantity and auto order quantity are set to 100 and 200 respectively.

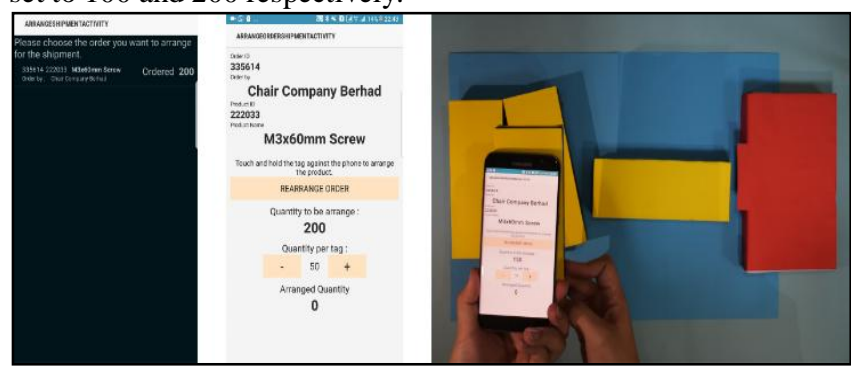

Fig. 11: Order arrangement activity

From an android managing application, the order received by the supplier needs to be arranged and write into the smart tags before shipment. Fig. 11 shows the interface of the android managing application which is used to write the order information into the smart tags according to the quantity set for each tag.

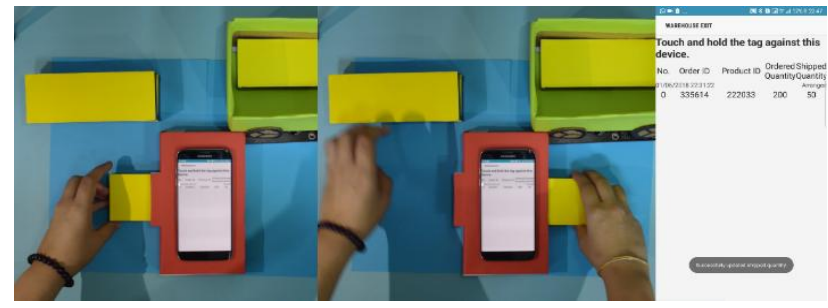

Fig. 12: Order exit gate activity

Fig. 12 shows the order that has been processed exiting the warehouse of the screw company through an order exit gate. Every order that passes through the exit gate for shipment is detected by the reader and the order status is updated in the server.

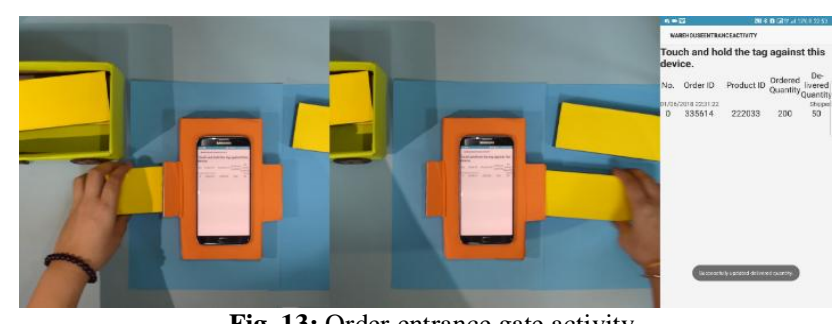

Fig. 13: Order entrance gate activity 
Fig. 13 shows the ordered supply arriving at the loading bay of the warehouse of the chair company. It will go through an order entrance gate. Every ordered supply that goes through the entrance gate is detected by the reader and the materials will be stored in the warehouse. The shipment is completed and an order status is updated in the server.

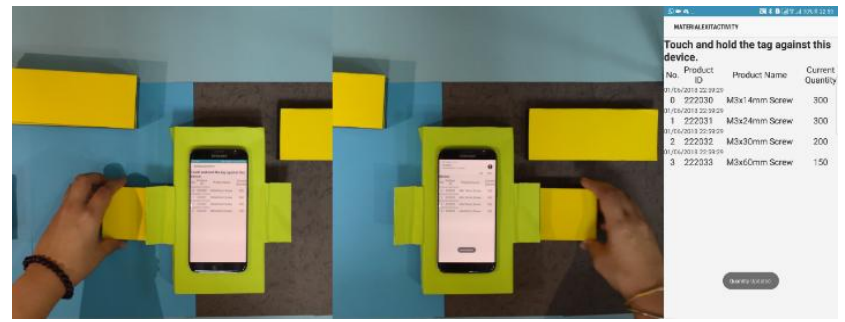

Fig. 14: Material exit gate activity

Fig. 14 shows the material exit from the warehouse to the production line. The material passes through a material exit gate and is again scanned by the reader. The current quantity of the materials in the warehouse is updated in the server. New order on the material will be made automatically depending on the setting once the current quantity is less than the required quantity set as shown in the Fig. 15.

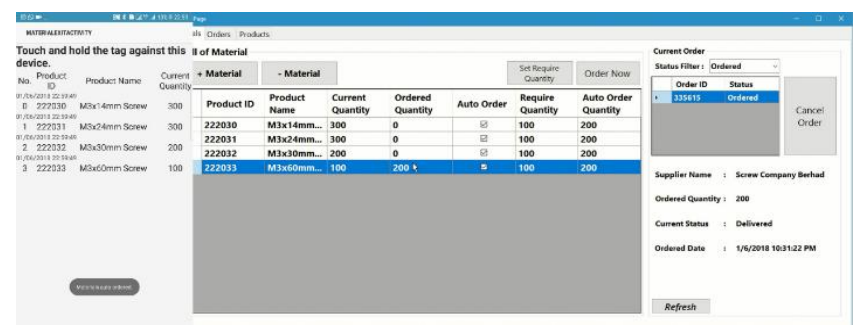

Fig. 15: New order made automatically

\section{System Evaluation}

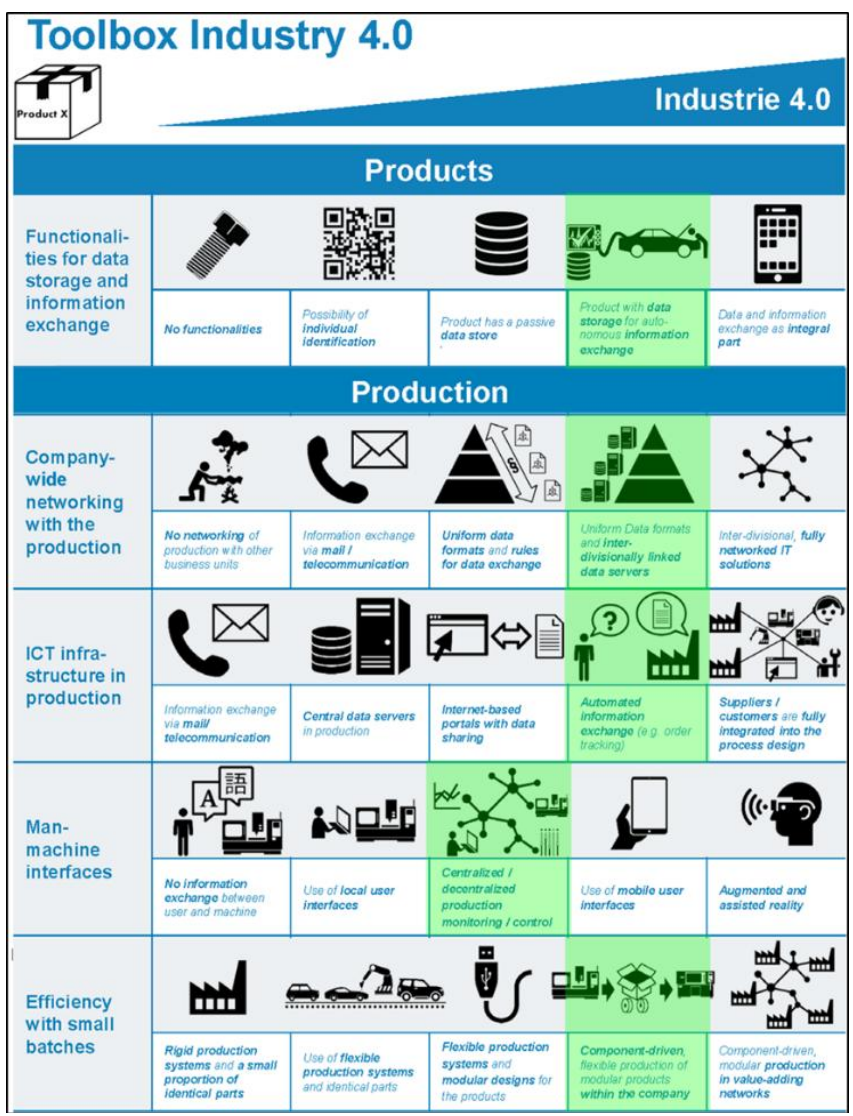

Fig. 16: Evaluated on selected units of toolbox industry 4.0
Fig. 16 shows the evaluation of the system using the Toolbox Industry 4.0 created by VDMA. Certain selected criteria related to the smart logistics management system in this project is evaluated. There are 5 units that have been selected for evaluation namely:

- Functionalities for data storage and information exchange Products in this system is able to store and exchange information either manually or automatically. This system uses NFC reader and tags for the exchange of data. The application has achieved level 4 in this criterion according to the Toolbox Industry 4.0. Products and materials in this project are attached with smart tags which can store various data to be exchanged.

- Company wide networking with the production

The networking between the supplier and manufacturer can improve the synergies and help to avoid work duplication. The networking between the production line and other facilities can standardized the work flows. In this project, a uniform data formats and inter-divisionally linked data server has been used where all the suppliers or manufacturers in this system uses the same format of login id, product id and order id.

- ICT infrastructure in production

Automated data exchanging process between the supply chains will add value to an interconnected network which is also

further step towards an Industry 4.0 vision. Therefore, automated information exchange is presented by the demonstration model of this smart logistics management system where all the orders' statuses are up-to-date automatically and can be viewed by both supply or manufacture partners.

\section{- Man-machine interfaces}

Production systems are getting more complex nowadays where the human-machine interaction becomes an important component. Mobile tablets or data glasses that can provide easy access to critical information with a goal to simplify the work of employees. This project has achieved a level there in this

criterion. Users can monitor and manage various data on the system especially concerning the materials through the monitoring and managing applications which is accessible using multiple platform or devices.

\section{- Efficiency with small batches}

The trend towards individually produced goods and continuously smaller batches leads to a rising complexity of production processes. Reaching higher efficiency with small lot sizes is thus becoming a decisive competitive factor. With this smart logistics management system, manufacturer would not worry about the insufficient of the materials or due to human errors which lead to decrease the production rate. Production of small batches can be done more efficiently by automatically managing the inventories.

\section{Conclusion}

This smart logistics management system is a conceptualize model as a basic start up platform for the manufacturers within this country to transform their factory into a smart factory. This aligns with the implementation of Industry 4.0 framework by the government of Malaysia. Malaysia needs to be ready for this revolution and be a competitive player to ensure the economic value of the country. Industry 4.0 is a set of rapidly evolving and converging technologies where other regional countries like Indonesia, India, Thailand and Singapore have aggressive plans and are moving fast in their implementation. This smart logistic management system provides a concept on applying an intelligence IoT system within the supply chain. The prototype demonstrator system has been evaluated based on its abilities and specifications in context of Industry 4.0 using the Toolbox Industry 4.0 from VDMA. According to the evaluation made, this system managed to achieve 
a remarkable average of level 4 out of 5 levels in the Industry 4.0 evaluation. Future works will focus on integrating the smart logistic system to a smart factory system to create a dynamic link between both systems.

\section{Acknowledgement}

The authors would like to express gratitude to the Office for Research, Innovation, Commercialization, Consultancy Management (ORICC), Universiti Tun Hussein Onn Malaysia for the Research and Innovation Fund.

\section{References}

[1] R. Y. Zhong, X. Xu, E. Klotz, and S. T. Newman, "Intelligent Manufacturing in the Context of Industry 4.0: A Review," Front. Mech. Eng., vol. In press, no. 5, pp. 616-630, 2017.

[2] U. Mohammad, C. Y. Low, J. Yee, and R. bin Abd Rahman, "Specification of principle solution for a smart factory exemplified by active structure," 2017 IEEE 3rd Int. Symp. Robot. Manuf. Autom., pp. 1-6, 2017.

[3] A. Radziwon, A. Bilberg, M. Bogers, and E. S. Madsen, "The smart factory: Exploring adaptive and flexible manufacturing solutions," Procedia Eng., vol. 69, pp. 1184-1190, 2014

[4] L. Domingo, "The Challenges of Logistics 4.0 for the Supply Chain Management and the Information Technology," Nor. Univ. Sci. Technol., no. May, pp. 1-84, 2016.

[5] M. Kirch, O. Poenicke, and K. Richter, "RFID in Logistics and Production -Applications, Research and Visions for Smart Logistics Zones," Procedia Eng., vol. 178, pp. 526-533, 2017.

[6] N. Wang and F. Xiao, "Design of Logistics Information Management System Based on Database," in 2010 Second International Conference on Computer Modeling and Simulation, 2010, pp. 111-115.

[7] Deborah Lee Soltesz, "The Advantages of a Relational Database Management System," 2017. [Online]. Available: https://www.techwalla.com/articles/the-advantages-of-a-relationaldatabase-management-system. [Accessed: 09-Dec-2017]. 